\title{
A New Kinetic Spectrophotometric Method for the Quantitation of Amorolfine
}

\author{
César Soto, ${ }^{1}$ Cristian Poza, ${ }^{1}$ David Contreras, ${ }^{1}$ Jorge Yáñez, \\ Fallon Nacaratte, ${ }^{2}$ and M. Inés Toral ${ }^{2}$ \\ ${ }^{1}$ Departamento de Química Analítica e Inorgánica, Facultad de Ciencias Químicas, Universidad de Concepción, Concepción, Chile \\ ${ }^{2}$ Laboratorio de Química Analítica, Facultad de Ciencias, Universidad de Chile, Santiago, Chile
}

Correspondence should be addressed to César Soto; cesarsoto@udec.cl

Received 10 October 2016; Revised 21 December 2016; Accepted 15 January 2017; Published 28 February 2017

Academic Editor: Christos Kontoyannis

Copyright (C) 2017 César Soto et al. This is an open access article distributed under the Creative Commons Attribution License, which permits unrestricted use, distribution, and reproduction in any medium, provided the original work is properly cited.

\begin{abstract}
Amorolfine (AOF) is a compound with fungicide activity based on the dual inhibition of growth of the fungal cell membrane, the biosynthesis and accumulation of sterols, and the reduction of ergosterol. In this work a sensitive kinetic and spectrophotometric method for the AOF quantitation based on the AOF oxidation by means of $\mathrm{KMnO}_{4}$ at $30 \mathrm{~min}$ (fixed time), $\mathrm{pH}$ alkaline, and ionic strength controlled was developed. Measurements of changes in absorbance at $610 \mathrm{~nm}$ were used as criterion of the oxidation progress. In order to maximize the sensitivity, different experimental reaction parameters were carefully studied via factorial screening and optimized by multivariate method. The linearity, intraday, and interday assay precision and accuracy were determined. The absorbance-concentration plot corresponding to tap water spiked samples was rectilinear, over the range of 7.56 $\times 10^{-6}-3.22 \times 10^{-5} \mathrm{~mol} \mathrm{~L}^{-1}$, with detection and quantitation limits of $2.49 \times 10^{-6} \mathrm{~mol} \mathrm{~L}^{-1}$ and $7.56 \times 10^{-6} \mathrm{~mol} \mathrm{~L}^{-1}$, respectively. The proposed method was successfully validated for the application of the determination of the drug in the spiked tap water samples and the percentage recoveries were $94.0-105.0 \%$. The method is simple and does not require expensive instruments or complicated extraction steps of the reaction product.
\end{abstract}

\section{Introduction}

Fungi are widely distributed in nature and most of them are pathogens which are the major causes of morbidity and mortality in patients with compromised immune systems (cancer, polytrauma, and HIV) that present a high risk of infection by opportunistic organisms [1,2]. In recent decades, therapeutic treatments for systemic fungal diseases have improved and expanded their use through more effective and less toxic novel drugs $[3,4]$. New fungicides, such as amorolfine $(\mathrm{AOF})$ or $(2 \mathrm{R}, 6 \mathrm{~S})$-rel-4-[3-[4-(1,1-dimethylpropyl)phenyl]-2-methylpropyl]-2,6-dimethyl-morpholine hydrochloride (Figure 1), have been incorporated into existing fungicides. This drug is a morpholine derivate [5] owning fungicide activity in a broad spectrum. This activity is based on the dual inhibition of growth of the fungal cell membrane and the action on the biosynthesis of sterols, producing their accumulation and reducing the amount of ergosterol
$[6,7]$. Topical presentation used for treatment of skin and nails is widely used [8]. A few methods for the quantitative determination of AOF in all types of samples (biological, environmental, and pharmaceutical) have been reported, including HPLC $[9,10]$ and spectrophotometric method [11]. In recent years kinetic spectrophotometric methods $[12,13]$ have been used for the determination of pharmaceutical compounds [14-17], in biological fluids [18], and natural and tap water [19-25]. These methods are suitable due to their characteristics of specificity and sensitivity [26], since absorbance variation in the time is measured in nonequilibrium condition $[27,28]$.

This work describes the development and validation of a kinetic and spectrophotometric method for quantitation in low concentration of AOF in tap water spiked samples. The AOF oxidation by means of $\mathrm{KMnO}_{4}$ was used and the reaction product $\mathrm{K}_{2} \mathrm{MnO}_{4}$ [29] was spectrophotometric determined at $610 \mathrm{~nm}$. 
<smiles>CCC(C)(C)c1ccc(CC(C)CN2C[C@H](C)O[C@H](C)C2)cc1</smiles>

FIGURE 1: Amorolfine (AOF).

\section{Experimental}

2.1. Instruments. A Perkin Elmer Lambda 35 double beams spectrophotometer (USA) with $10 \mathrm{~mm}$ quartz cells was used for measurements. For all solutions, the spectra were recorded on the range between 190 and $800 \mathrm{~nm}$ against blank, using sampling intervals of $0.2 \mathrm{~nm}$ with a scan speed of $480 \mathrm{~nm} \mathrm{~min}{ }^{-1}$. The spectral data were processed by Perkin Elmer UV Win Lab Data Processor and Viewer 1.00. The solid samples were weighted with a $\pm 0.01 \mathrm{mg}$ of uncertainty using AS 60/220/C/2 analytical balance.

2.2. Reagents. AOF was purchased from Toronto Chemical Research, TCR $^{\circledR}$ (Canada). All reagents were of analytical reagent grade and all solutions were prepared with Milli$\mathrm{Q}$ water. Stock solutions of $1.11 \times 10^{-3} \mathrm{~mol} \mathrm{~L}^{-1}$ of AOF were prepared by dissolving $10.0 \mathrm{mg}$ and diluting $25 \mathrm{~mL}$ with deionized water in a volumetric flask. The same solution was used to prepare samples with different concentrations by appropriate dilution using deionized water. Aqueous solutions of $\mathrm{NaOH} 1.0 \mathrm{~mol} \mathrm{~L}^{-1}, \mathrm{KMnO}_{4} 9.8 \times 10^{-2} \mathrm{~mol} \mathrm{~L}^{-1}$, and $\mathrm{Na}_{2} \mathrm{SO}_{4} 2.0 \mathrm{~mol} \mathrm{~L}^{-1}$ were prepared from Merck (Germany) reagents.

\section{Procedures}

3.1. Kinetic Procedure. Samples were prepared using accurately aliquots of $\mathrm{AOF}$ stock solutions that were transferred into $5 \mathrm{~mL}$ volumetric flasks. Proper amounts of $\mathrm{KMnO}_{4} 9.8$ $\times 10^{-2} \mathrm{~mol} \mathrm{~L}^{-1}, \mathrm{NaOH} 1.0 \mathrm{~mol} \mathrm{~L}^{-1}$, and $\mathrm{Na}_{2} \mathrm{SO}_{4} 2.0 \mathrm{~mol} \mathrm{~L}^{-1}$ were added to achieve the oxidation reaction in optimal conditions. The samples were heated in water bath at $50 \pm 0.1^{\circ} \mathrm{C}$ for $30 \mathrm{~min}$ and the absorbance of solutions was measured at $610 \mathrm{~nm}$. External calibration using prepared standards of AOF and blank in the range $6.0 \times 10^{-6}$ to $5.0 \times 10^{-5} \mathrm{~mol} \mathrm{~L}^{-1}$ was carried out. Thereafter, the corresponding regression equation is attained. Furthermore, $\log v$ v/s $\log [\mathrm{AOF}]$ was plotted to get the order of the reaction.

3.2. Factorial Optimization Parameters. In order to optimize the reaction, an experimental design with statistical software (Modde 7) was used, considering a factorial design $2^{4}$ using the factors on Table 1 . Then a circumscribed central composite design (CCC) was performed, using the factors $\mathrm{NaOH}$ concentration $\left(0.18,0.26\right.$, and $\left.0.34 \mathrm{~mol} \mathrm{~L}^{-1}\right)$ and temperature $\left(50,65\right.$, and $\left.80^{\circ} \mathrm{C}\right)$ and maintaining $\mathrm{KMnO}_{4}$ $9.0 \times 10^{-4} \mathrm{~mol} \mathrm{~L}^{-1}, \mathrm{Na}_{2} \mathrm{SO}_{4} 0.2 \mathrm{~mol} \mathrm{~L}^{-1}$. For optimization
TABLE 1: Coded values for the factorial design.

\begin{tabular}{lccc}
\hline Factor & -1 & 0 & +1 \\
\hline $\mathrm{KMnO}_{4}\left(\times 10^{-4} \mathrm{~mol} \mathrm{~L}^{-1}\right)$ & 7 & 8 & 9 \\
$\mathrm{Na}_{2} \mathrm{SO}_{4}\left(\mathrm{~mol} \mathrm{~L}^{-1}\right)$ & 0.2 & 0.3 & 0.4 \\
$\mathrm{NaOH}\left(\mathrm{mol} \mathrm{L}^{-1}\right)$ & 0.018 & 0.09 & 0.18 \\
Temperature $\left({ }^{\circ} \mathrm{C}\right)$ & 35 & 50 & 65 \\
\hline
\end{tabular}

AOF concentration was $2.3 \times 10^{-5} \mathrm{~mol} \mathrm{~L}^{-1}$ and the response used was the absorbance at $610 \mathrm{~nm}$ after $30 \mathrm{~min}$ of reaction time.

3.3. Procedure for Determination of AOF in Tap Water Spiked Samples. The developed method was applied for the quantitation of AOF in spiked tap water samples. The samples analyzed $(500 \mathrm{~mL})$ were gathered from taps located in two labs. The samples were collected in polyethylene bottles without adding any preservative agent and analyzed within $5 \mathrm{~h}$. In order to remove the suspended fine particles (organic and inorganic matter) and dissolved gases, which are considered as potential interferences that can be oxidized by $\mathrm{KMnO}_{4}$, the samples were boiled $(5 \mathrm{~min})$ and filtered $(0.25 \mu \mathrm{m})$. Aliquots of the tap water were spiked with known concentrations of $\mathrm{AOF}$ and then the samples were prepared according to the procedure described above.

\section{Results and Disscusions}

Permanganate in alkaline medium was used in the development of a kinetic method for the determination of AOF. The oxidation of this drug under specific conditions of $\mathrm{pH}$ and ionic strength causes color changes to bluish green corresponding to the manganate $\mathrm{K}_{2} \mathrm{MnO}_{4}$ (the main reaction product) producing new absorption bands at 450 and $610 \mathrm{~nm}$. The intensity of the color increases with the concentration of this reaction product. The influences of the following variables, reaction time $(t)$, temperature $\left(T^{\circ}\right)$, concentrations of $\mathrm{NaOH}(\mathrm{pH}), \mathrm{KMnO}_{4}$, and $\mathrm{Na}_{2} \mathrm{SO}_{4}$ (effect of ionic strength), were studied by the univariate method. Then only the variables involved in the formation of $\mathrm{K}_{2} \mathrm{MnO}_{4}$ were optimized. The reaction was monitored at $610 \mathrm{~nm}$ using AOF $2.2 \times 10^{-5} \mathrm{~mol} \mathrm{~L}^{-1}$.

4.1. Variables Studies. The effect of the temperature on the reaction rate over the range 20 to $65^{\circ} \mathrm{C}$ was studied (Figure 2). The oxidation of AOF is favored by increasing temperature but from $50^{\circ} \mathrm{C}$ this effect decreases. This can be attributed to the permanganate self-decomposition over $65^{\circ} \mathrm{C}$. Therefore, the temperature was adjusted at $50^{\circ} \mathrm{C}$.

The effect of $\mathrm{KMnO}_{4}$ concentration was studied over the range $5.0 \times 10^{-4}-9.1 \times 10^{-4} \mathrm{~mol} \mathrm{~L}^{-1}$ (Figure 3 ). The results show that reaction rate increased as oxidant concentration augmented, evidencing a proportional dependence. Up to 8.0 $\times 10^{-4} \mathrm{~mol} \mathrm{~L}^{-1} \mathrm{KMnO}_{4}$ does not affect the reaction rate which depends on substrate concentration. This value was initially selected. 


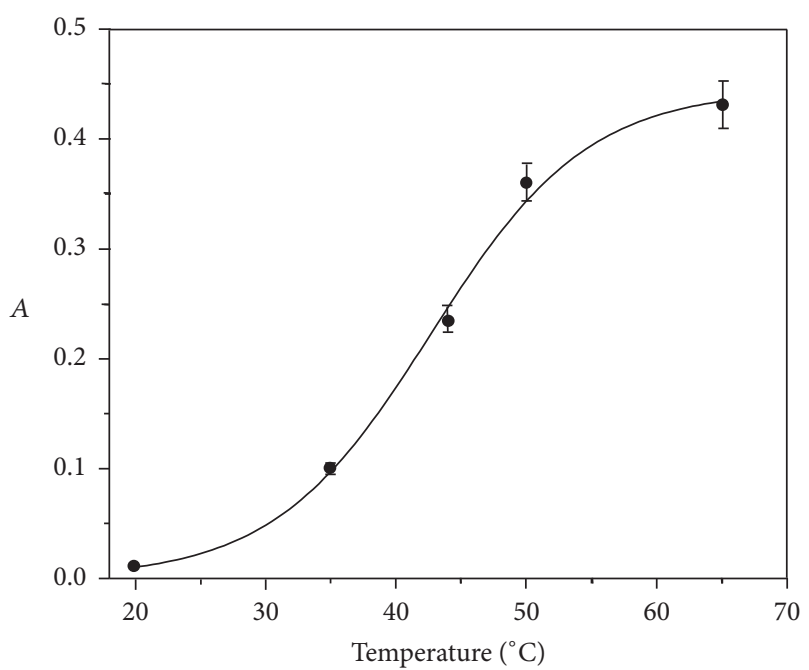

Figure 2: Effect of the temperature on the system AOF- $\mathrm{KMnO}_{4}$ $\left(2.3 \times 10^{-5}\right.$ and $9.0 \times 10^{-4} \mathrm{~mol} \mathrm{~L}^{-1}$, resp. $)$ with $\mathrm{Na}_{2} \mathrm{SO}_{4} 0.20 \mathrm{~mol} \mathrm{~L}^{-1}$, $\mathrm{NaOH} 0.30 \mathrm{~mol} \mathrm{~L}^{-1}$, monitoring at $610 \mathrm{~nm}$, and $t=30 \mathrm{~min}$.

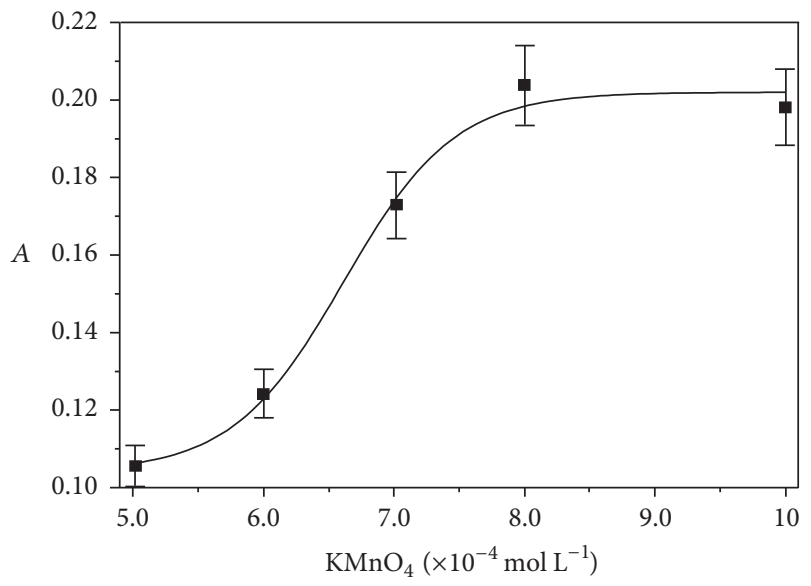

FIGURE 3: Concentration effect of $\mathrm{KMnO}_{4}\left(5.0 \times 10^{-4}-1.0 \times\right.$ $10^{-3} \mathrm{~mol} \mathrm{~L}^{-1}$ ) on the AOF- $\mathrm{KMnO}_{4}$ system, with AOF $2.2 \times$ $10^{-5} \mathrm{~mol} \mathrm{~L}^{-1}, \mathrm{Na}_{2} \mathrm{SO}_{4} 0.20 \mathrm{~mol} \mathrm{~L}^{-1}, \mathrm{NaOH} 0.30 \mathrm{~mol} \mathrm{~L}^{-1}, T^{\circ}=50^{\circ} \mathrm{C}, t$ $=30 \mathrm{~min}$, and monitoring at $610 \mathrm{~nm}$.

The AOF oxidation with $\mathrm{KMnO}_{4}$ takes place in alkaline medium. The study of the medium effect $(\mathrm{pH})$ was carried out with different $\mathrm{NaOH}$ concentrations ranging from $4.0 \times$ $10^{-4}$ to $0.56 \mathrm{~mol} \mathrm{~L}^{-1}$ (Figure 4). Experimentally the stability of $\mathrm{K}_{2} \mathrm{MnO}_{4}$ (reduction product) occurred in the range of 0.018 and $0.34 \mathrm{~mol} \mathrm{~L}^{-1}$.

The effect of time of reaction $(t)$ was also studied by measuring the absorbance at the 0-60 min interval (Figure 5). The absorbance values increased proportionally up to $30 \mathrm{~min}$; longer time periods present negligible effects in absorbance values. Hence, $30 \mathrm{~min}$ of reaction time was selected.

Additionally, the effect of $\mathrm{Na}_{2} \mathrm{SO}_{4}$ concentration (ionic strength), on the reaction rate, was studied (Figure 6). Since the variation of this concentration did not affect AOF

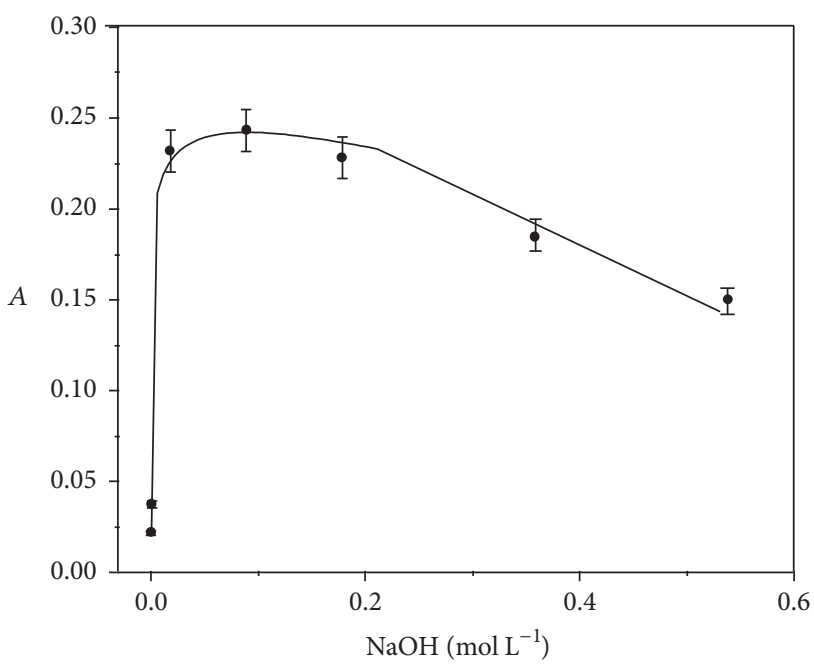

FIgure 4: Concentration effect of $\mathrm{NaOH}\left(4.0 \times 10^{-4}-0.56 \mathrm{~mol} \mathrm{~L}^{-1}\right)$ on the AOF- $\mathrm{KMnO}_{4}$ system, with AOF $2.3 \times 10^{-5} \mathrm{~mol} \mathrm{~L}^{-1}, \mathrm{KMnO}_{4}$ $9.0 \times 10^{-4} \mathrm{~mol} \mathrm{~L}^{-1}, \mathrm{Na}_{2} \mathrm{SO}_{4} 0.20 \mathrm{~mol} \mathrm{~L}^{-1}, t=30 \mathrm{~min}, T^{\circ}=50^{\circ} \mathrm{C}$, and monitoring at $610 \mathrm{~nm}$.

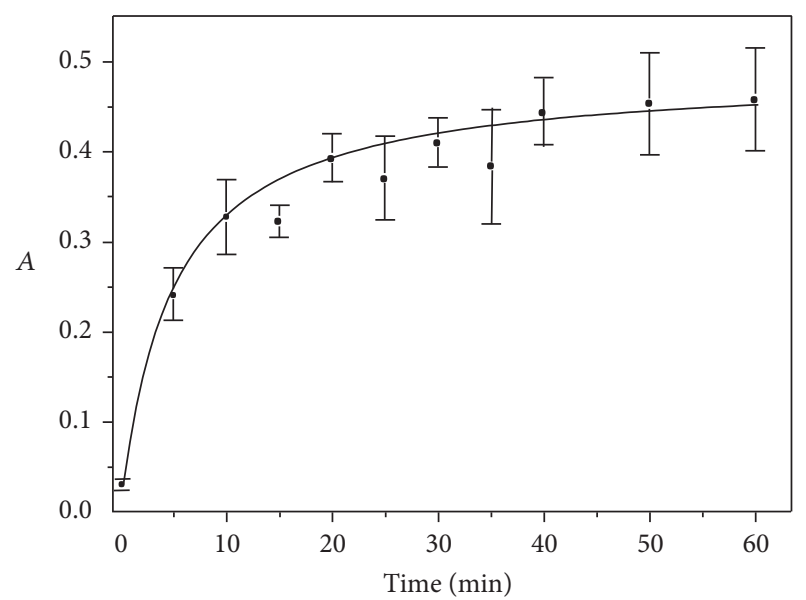

Figure 5: Effect of reaction time $(t)$ on the AOF- $\mathrm{KMnO}_{4}$ system, at $\mathrm{NaOH} 0.34 \mathrm{~mol} \mathrm{~L}^{-1}$, AOF $2.3 \times 10^{-5} \mathrm{~mol} \mathrm{~L}^{-1}, \mathrm{KMnO}_{4} 9.0 \times$ $10^{-4} \mathrm{~mol} \mathrm{~L}^{-1}, \mathrm{NaOH} 0.30 \mathrm{~mol} \mathrm{~L}^{-1}, \mathrm{Na}_{2} \mathrm{SO}_{4} 0.20 \mathrm{~mol} \mathrm{~L}^{-1}, T^{\circ}=50^{\circ} \mathrm{C}$, and monitoring at $610 \mathrm{~nm}$.

oxidation, $0.2 \mathrm{~mol} \mathrm{~L}^{-1}$ was used to maintain constant ionic strength.

4.2. Variables Optimization. Considering the above results, a factorial design $2^{4}$ was performed, using the factors presented in Table 1 . The $t$ and AOF concentration values used were $30 \mathrm{~min}$ and $2.3 \times 10^{-5} \mathrm{~mol} \mathrm{~L}^{-1}$, respectively. The results showed that the reaction is influenced mainly by the temperature and $\mathrm{NaOH}$ concentration (Figure 7). In order to optimize the reaction a circumscribing central composite design (CCC) was applied considering these 2 variables using the values indicated on Section 3.2 and constant values for

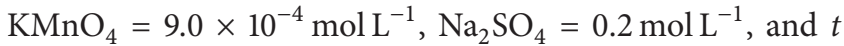
$=30 \mathrm{~min}$. The optimal values obtained from the model were 

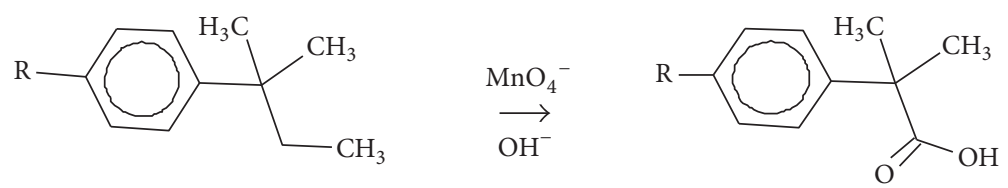

Scheme 1: Reaction between $\mathrm{AOF}$ and $\mathrm{KMnO}_{4}$ in alkaline medium.

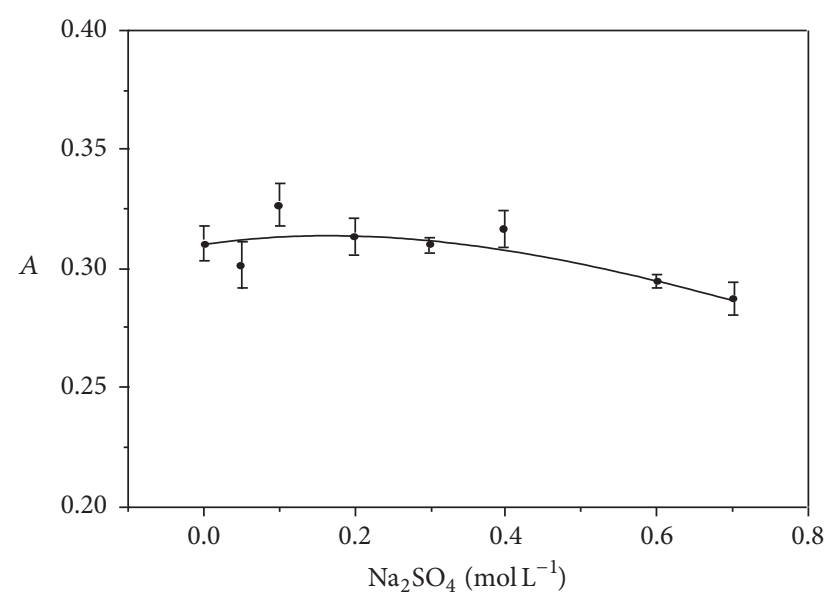

Figure 6: Concentration effect of $\mathrm{Na}_{2} \mathrm{SO}_{4}\left(0-0.7 \mathrm{~mol} \mathrm{~L}^{-1}\right)$ on the $\mathrm{AOF}-\mathrm{KMnO}_{4}$ system, with AOF $2.3 \times 10^{-5} \mathrm{~mol} \mathrm{~L}^{-1}, \mathrm{NaOH}$ $0.30 \mathrm{~mol} \mathrm{~L}^{-1}, \mathrm{KMnO}_{4} 9.0 \times 10^{-4} \mathrm{~mol} \mathrm{~L}^{-1}, t=30 \mathrm{~min}, T^{\circ}=50^{\circ} \mathrm{C}$, and monitoring at $610 \mathrm{~nm}$.

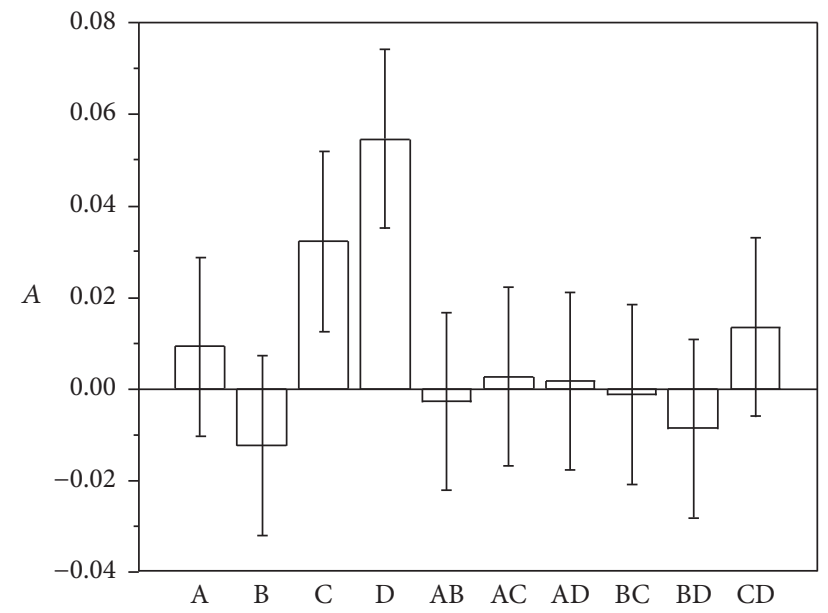

FIGURE 7: Influence of variables on the $\mathrm{AOF}-\mathrm{KMnO}_{4}$ system for the factorial design $\left(\mathrm{A}=\mathrm{KMnO}_{4} ; \mathrm{B}=\mathrm{Na}_{2} \mathrm{SO}_{4} ; \mathrm{C}=\mathrm{NaOH}\right.$; and $\left.\mathrm{D}=T^{\circ}\right)$.

temperature $86^{\circ} \mathrm{C}$ and $\mathrm{NaOH} 0.26 \mathrm{~mol} \mathrm{~L}^{-1}$ (Figure 8). Temperature values above $65^{\circ} \mathrm{C}$ cause the precipitation of $\mathrm{MnO}_{2}$; then the experimental work is achievable at a lower temperature, where $50^{\circ} \mathrm{C}$ was selected. Using this value the model maximizes the response signal with $\mathrm{NaOH} 0.34 \mathrm{~mol} \mathrm{~L}^{-1}$. In the experimental verification, the values predicted by the model were obtained.

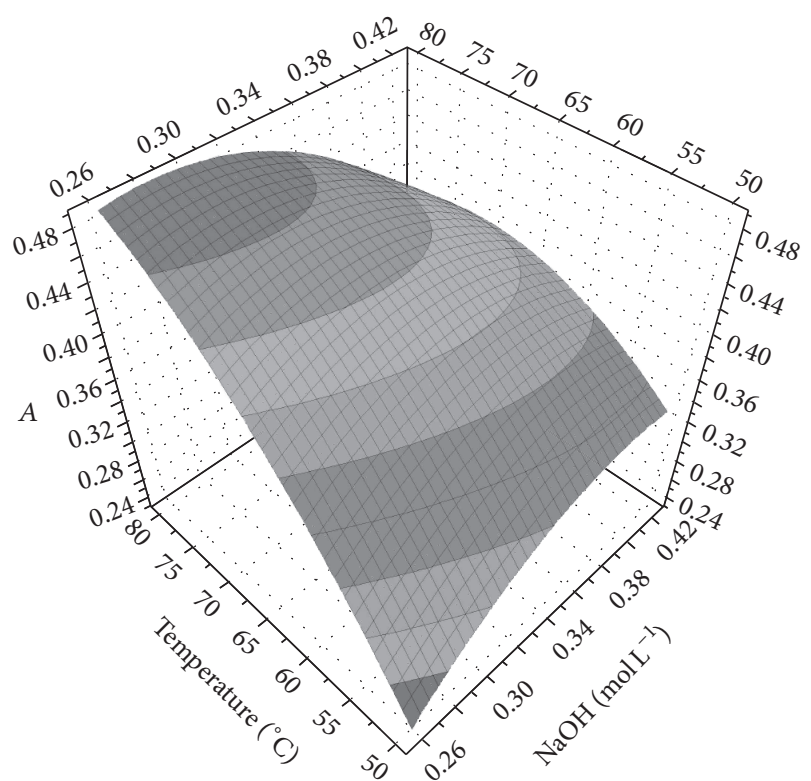

FIGURE 8: Graphic response surface of the circumscribing central composite design (CCC) for the AOF- $\mathrm{KMnO}_{4}$ system.

4.3. Stoichiometry Determination. The stoichiometry of the reaction was studied using optimized experimental conditions, monitoring at $610 \mathrm{~nm}$ and the limit logarithmic method [30]. A plot of $\log A \mathrm{v} / \mathrm{s} \log [\mathrm{AOF}]$ at a constant $\mathrm{KMnO}_{4}$ concentration gave a straight line with a slope of 0.723 . A plot of $\log A \mathrm{v} / \mathrm{s} \log \left[\mathrm{KMnO}_{4}\right]$ at a constant AOF concentration gave a straight line with a slope of 0.685 . Thus, the molar ratio of the reaction is $0.723: 0.685 \approx 1: 1$. Based on the obtained molar relation and other similar reactions described [29], the alkyl group (1,1-dimethylpropyl in our case) attached to the aromatic ring was oxidized more easily than the other groups. The propyl group is oxidized by $\mathrm{KMnO}_{4}$ in alkaline conditions turning into the corresponding carboxilic acid in which the permanganate is reduced to the manganate (colored species). The proposed reaction pathway is shown in Scheme 1.

4.4. Kinetic of the Reaction. Considering the pseudo-first order reaction conditions $\left(\left[\mathrm{KMnO}_{4}\right]>[\mathrm{AOF}]\right)$ and the optimized variables, the kinetic behavior of reaction can be represented by the equation $v=k^{\prime}[\mathrm{AOF}]^{n}$, with the plot of $\log v \mathrm{v} / \mathrm{s} \log [\mathrm{AOF}]$, the order of reaction $(n)$ and rate constant $\left(k^{\prime}\right)$ were obtained, and the values were $0.938(\approx 1)$ and $4.70 \mathrm{~s}^{-1}$, respectively. 
TABLE 2: Calibration curves and statistical parameters for different fixed times at $50^{\circ} \mathrm{C}$, monitoring at $610 \mathrm{~nm}$ and $\mathrm{AOF}$ concentration ranging between $6.0 \times 10^{-6}$ and $3.0 \times 10^{-5} \mathrm{~mol} \mathrm{~L}^{-1}$.

\begin{tabular}{lccccccc}
\hline Parameters & $0 \mathrm{~min}$ & $10 \mathrm{~min}$ & $20 \mathrm{~min}$ & $30 \mathrm{~min}$ & $40 \mathrm{~min}$ & $50 \mathrm{~min}$ & $60 \mathrm{~min}$ \\
\hline$R^{2}$ & 0.9899 & 0.8744 & 0.9161 & 0.9544 & 0.9345 & 0.9426 & 0.9619 \\
Typical error & 0.00462 & 0.0587 & 0.0595 & 0.0538 & 0.0812 & 0.0617 & 0.0490 \\
$t_{\text {calculated }}$ & 17.15 & 4.570 & 5.726 & 7.926 & 5.114 & 7.019 \\
Intercept & 0.00250 & 0.0461 & 0.0562 & 0.0472 & 0.0838 & 0.1124 \\
Slope $\left(\times 10^{3}\right)$ & 2.244 & 7.600 & 9.655 & 12.09 & 11.77 & 12.27 \\
\hline
\end{tabular}

$t_{\text {critic }(P=0,05, n-2)}=3.18, N=5$.

4.5. Evaluation of the Kinetic Methods. The pseudo-first order reaction rate $\left(v=4.70 \mathrm{~s}^{-1}[\mathrm{AOF}]^{0.938}\right)$ was the basis for several experiments conducted to obtain AOF concentration. The kinetic methods of initial rate, constant rate, and fixed time were tried and selected based on the applicability, sensitivity, intercept, and $R^{2}$. The first two methods were discarded, because they presented low linearity, reproducibility, and sensitivity. It was concluded that the fixed time method presents linear correlation for each value of time studied.

Initial Rate. The curves of absorbance (at $610 \mathrm{~nm}$ ) v/s $t(\mathrm{~s})$ are obtained for AOF concentrations over the range $6.0 \times 10^{-6}$ to $5.0 \times 10^{-5} \mathrm{~mol} \mathrm{~L}^{-1}$ of AOF. Then, tangents were drawn for each curve with $t=250 \mathrm{~s}$. Afterwards, the respective slopes $\left(K^{\prime \prime}\right)$ were obtained. Equation (1) was obtained from the graph of $K^{\prime \prime} \mathrm{v} / \mathrm{s}$ [AOF] and it corresponds to a kinetic behavior of pseudo-zero order (no determining step of the reaction). $R^{2}$ and slope values indicate low linearity and sensitivity, respectively. For this reason this method was discarded.

$$
\begin{aligned}
K^{\prime \prime} & =7.33 C+2.51 \times 10^{-5}, \\
R^{2} & =0.8749 .
\end{aligned}
$$

Constant Rate. For this method, the plots of $\log A$ (at $610 \mathrm{~nm}$ ) $\mathrm{v} / \mathrm{s} t(0-1800 \mathrm{~s})$ for range of AOF concentration of $6.0 \times 10^{-6}$ to $5.0 \times 10^{-5} \mathrm{~mol} \mathrm{~L}^{-1}$ were performed, obtaining straight lines, with slope $=K^{\prime} / 2.303$ (pseudo-first order). Then, the drug concentration v/s $K^{\prime}$ was plotted (2). Although this method produces a better linear correlation with respect to the initial rate, the low slope makes it impossible to obtain the necessary parameters to develop an analytical method.

$$
\begin{aligned}
& K^{\prime}=0.720 C-4.40 \times 10^{-4}, \\
& R^{2}=0.9431 .
\end{aligned}
$$

Fixed Time. In this method a preselected group of fixed time values was accurately measured (0 to $60 \mathrm{~min}$ ). For each one, linear equations and statistical parameters were obtained, considering a Student's $t$-test (two-tailed) with $n-2$ degrees of freedom (Table 2). Considering an invalid correlation between AOF concentration and measured absorbance (Null hypothesis $\mathrm{H}_{0}$ ), the results gave $t_{\text {calculated }}>t_{\text {critic }}$ for each time value, causing the hypothesis refusal and confirming the linear behavior for each time value. The linear and statistical parameters, for $t=30 \mathrm{~min}$, were optimal. Since this method
TABLE 3: Analytical parameters using AOF standards solutions.

\begin{tabular}{lc}
\hline Parameters & Values \\
\hline Linear regression & $A=1.364 \times 10^{4} \mathrm{C}+5.20 \times 10^{-3}$ \\
$R^{2}$ & 0.997 \\
$\mathrm{LOD}^{*}\left(\mathrm{~mol} \mathrm{~L}^{-1}\right)$ & $2.39 \times 10^{-6}$ \\
$\mathrm{LOQ}^{*}\left(\mathrm{~mol} \mathrm{~L}^{-1}\right)$ & $7.25 \times 10^{-6}$ \\
Linear range $(\mathrm{mol} \mathrm{L}$ & $-1)$ \\
$\sigma$ (blanks) & $7.25 \times 10^{-6}-3.22 \times 10^{-5}$ \\
\hline
\end{tabular}

${ }^{*} \mathrm{LOD}=3.3 \sigma / \mathrm{S}$ and $\mathrm{LOQ}=10 \sigma / \mathrm{S}$.

shows a marked increase in sensitivity it was selected for the determination of AOF.

4.6. Calibration Curve and Analytical Parameters Using AOF Standards Solutions. Using the previously selected experimental conditions, the analytical parameters were obtained for drug standard solutions with 11 independent reagent blanks (without analyte) (Table 3).

The accuracy and precision were evaluated for three AOF concentrations $\left(8.00 \times 10^{-6} ; 10.0 \times 10^{-6} ; 30.0 \times 10^{-6} \mathrm{~mol} \mathrm{~L}^{-1}\right)$, through the recoveries and Student's $t$-test, respectively. Recoveries for intraday and interday (Table 4) were obtained, with 30 blanks in 5 consecutive days of measurement, with Student's $t$-test of $95 \%$ confidence percentage and $n-1$ degrees of freedom. The results gave $t_{\text {calculated }}<t_{\text {critic }}$, indicating that the differences between observed and expected values are acceptable given the confidence percentage established as criterion of acceptability. These results indicated satisfactory repeatability and precision. The recoveries are between 101.3 and $106.5 \%$, presenting a satisfactory accuracy for kineticanalytical methods evaluated.

4.7. Validation and Application. The validation of the above procedure was carried out in tap water samples fortified with three levels of AOF concentration $\left(8.00 \times 10^{-6} ; 10.0 \times 10^{-6}\right.$; $\left.30.0 \times 10^{-6} \mathrm{~mol} \mathrm{~L}^{-1}\right)$ following the procedures of Section 3.3. For this, a calibration curve was prepared in tap water $(2.3 \times$ $10^{-6}-3.2 \times 10^{-5} \mathrm{~mol} \mathrm{~L}^{-1}$ ) using the respective blanks (without $\mathrm{AOF}$ ). With these results, the analytical parameters indicated in the Table 5 were obtained.

Afterwards, intraday and interday assays of a group of 30 blanks were realized; measurements were carried out for five consecutive days. With these results, the standard deviation was determined (Table 6). In order to assess the accuracy of the method, recoveries were obtained using three 
TABLE 4: Analysis to assess the precision and accuracy of the proceeding developed for the determination of AOF intraday and interday.

\begin{tabular}{|c|c|c|c|c|c|c|}
\hline Added $\left(\times 10^{-6} \mathrm{~mol} \mathrm{~L}^{-1}\right)$ & Found $\left(\times 10^{-6} \mathrm{~mol} \mathrm{~L}^{-1}\right)$ & $\sigma \times 10^{-7}$ & $\mathrm{ES}^{*} \times 10^{-7}$ & Confidence limits $^{\dagger} \times 10^{-7}$ & $t_{\mathrm{cal}^{*}}$ & Recovery (\%) \\
\hline \multicolumn{7}{|c|}{ Intraday } \\
\hline 8.00 & 8.10 & 2.68 & 1.55 & 6.66 & 0.219 & 101.3 \\
\hline 10.0 & 10.6 & 106 & 69.9 & 3.00 & 3.09 & 106.5 \\
\hline 30.0 & 32.2 & 322 & 1.18 & 5.08 & 3.49 & 103.9 \\
\hline \multicolumn{7}{|c|}{ Interday } \\
\hline 8.00 & 8.40 & 6.76 & 3.90 & 0.0167 & 3.42 & 105.0 \\
\hline 10.0 & 10.5 & 6.97 & 4.02 & 0.0173 & 4.14 & 105.0 \\
\hline 30.0 & 32.2 & 6.10 & 3.52 & 0.0151 & 11.4 & 103.9 \\
\hline
\end{tabular}

${ }^{*}$ Error standard deviation, ${ }^{\dagger}$ confidence limits $\left(\mathrm{mol} \mathrm{L}^{-1}\right)$ with $95 \%$ and 5 degrees of freedom for intraday and for interday assays $\left(t_{\text {critic }}=4.3\right)$, and ${ }^{\star} t_{\text {cal }}=$ $t_{\text {calculated. }}$.

TABLE 5: Analytical parameters for the AOF determination using a calibration curve in tap water.

\begin{tabular}{lr}
\hline Parameters & Values \\
\hline Linear regression & $A=1.31 \times 10^{4} \mathrm{C}+0.0111$ \\
$R^{2}$ & 0.999 \\
$\mathrm{LOD}^{*}\left(\mathrm{~mol} \mathrm{~L}^{-1}\right)$ & $2.49 \times 10^{-6}$ \\
$\mathrm{LOQ}^{*}\left(\mathrm{~mol} \mathrm{~L}^{-1}\right)$ & $7.56 \times 10^{-6}$ \\
Concentration range $\left(\mathrm{mol} \mathrm{L}^{-1}\right)$ & $7.56 \times 10^{-6}-3.22 \times 10^{-5}$ \\
$\sigma$ (blanks) & $9.90 \times 10^{-3}$ \\
\hline
\end{tabular}

${ }^{*}$ LOD: $3.3 \sigma /$ S; LOQ: $10 \sigma / S$.

TABLE 6: Analysis to assess precision and accuracy of the developed method for the determination of AOF intraday and interday.

\begin{tabular}{|c|c|c|c|c|c|c|}
\hline Added $\left(\times 10^{-6} \mathrm{~mol} \mathrm{~L}^{-1}\right)$ & Found $\left(\times 10^{-6} \mathrm{~mol} \mathrm{~L}^{-1}\right)$ & $\sigma \times 10^{-7}$ & $\mathrm{ES}^{*} \times 10^{-7}$ & Confidence limits ${ }^{\dagger} \times 10^{-7}$ & $t_{\mathrm{cal}}{ }^{\star}$ & Recovery (\%) \\
\hline \multicolumn{7}{|c|}{ Intraday } \\
\hline 8.00 & 7.52 & 5.86 & 2.39 & 6.15 & 0.469 & 94.0 \\
\hline 10.0 & 10.2 & 4.68 & 1.91 & 4.92 & 0.291 & 102.4 \\
\hline 30.0 & 30.2 & 2.70 & 1.10 & 2.84 & 0.514 & 100.8 \\
\hline \multicolumn{7}{|c|}{ Interday } \\
\hline 8.00 & 8.23 & 6.13 & 3.54 & 1.52 & 0.216 & 102.9 \\
\hline 10.0 & 10.5 & 11.5 & 6.65 & 2.86 & 0.257 & 105.1 \\
\hline 30.0 & 30.3 & 12.6 & 7.25 & 3.12 & 0.142 & 101.0 \\
\hline
\end{tabular}

${ }^{*}$ Error standard deviation, ${ }^{\dagger}$ confidence limits $\left(\mathrm{mol} \mathrm{L}^{-1}\right)$ with $95 \%$ and 5 degrees of freedom for intraday and for interday assays $\left(t_{\text {critic }}=4.3\right) ;{ }^{*} t_{\text {cal }}=t_{\text {calculated }}$.

analyte concentrations, mentioned above. The recoveries of the intraday and interday assays were $94.0-102.4 \%$ and $101.0-105.0 \%$ presenting a satisfactory accuracy for kineticanalytical method selected (Table 6). The effect of the possible interfering was eliminated through the application of the procedure of Section 3.3.

The method was applied in spiked tap water samples with three known amounts of AOF and then analyzed individually (6 repetitions) according to the respective procedure. The linear regression equation obtained in Section 4.7 was used in the AOF quantitation. For the proposed samples the statistical analysis of these results using Student's $t$-test showed that there was no significant difference between the real and found concentrations at the $95 \%$ confidence level (Table 6 , intraday).

\section{Conclusions}

In this study a kinetic spectrophotometric method based on the AOF oxidation with $\mathrm{KMnO}_{4}$ in alkaline medium to form to $\mathrm{MnO}_{4}{ }^{2-}$ was carried out. Optimal results were obtained by measuring the oxidation kinetic of AOF- $\mathrm{KMnO}_{4}$ system using $9.0 \times 10^{-4} \mathrm{~mol} \mathrm{~L}^{-1} \mathrm{KMnO}_{4}, 50^{\circ} \mathrm{C}, 0.20 \mathrm{~mol} \mathrm{~L}^{-1}$ $\mathrm{Na}_{2} \mathrm{SO}_{4}$, and $0.34 \mathrm{~mol} \mathrm{~L}^{-1} \mathrm{NaOH}$ for $30 \mathrm{~min}$. The molar relation $\mathrm{AOF}: \mathrm{KMnO}_{4}$ was determined using the previously stated variable values and was $1: 1$.

The kinetics studies were carried out considering three methods: initial rate, constant rate, and fixed time. The most suitable method was the fixed time at $30 \mathrm{~min}$, because it presented satisfactory values of analytical parameters $\left(R^{2}\right.$ and slope). To assay the accuracy and reliability of the AOF determination in the proposed sample several assays were carried out and showed statistically satisfactory results with the recoveries and the respective Student's $t$-test. This method is simple and does not require expensive instruments and complicated extraction steps of the reaction product. 


\section{Competing Interests}

The authors declare that there is no conflict of interests regarding the publication of this paper.

\section{Acknowledgments}

The authors are grateful to the Fondo Nacional de Investigación en Ciencia y Tecnología (FONDECYT), Project no. 1130398, and CONICYT Doctoral Fellowship no. 21120686, for the financial support.

\section{References}

[1] R. J. Ekiert, J. Krzek, and P. Talik, "Chromatographic and electrophoretic techniques used in the analysis of triazole antifungal agents-a review," Talanta, vol. 82, no. 4, pp. 10901100, 2010.

[2] J. C. R. Corrêa and H. R. N. Salgado, "Review of fluconazole properties and analytical methods for its determination," Critical Reviews in Analytical Chemistry, vol. 41, no. 2, pp. 124-132, 2011.

[3] A. Bergold and S. Georgiadis, "Novidades em farmacos antifungicos: uma revisao," Visão Acadêmica, vol. 5, no. 2, pp. 159172,2004

[4] A. J. Carrillo-Muñoz, G. Giusiano, P. A. Ezkurra, and G. Quindós, "Antifungal agents: mode of action in yeast cells," Revista Espanola de Quimioterapia, vol. 19, no. 2, pp. 130-139, 2006.

[5] A. M. Polak, "Preclinical data and mode of action of amorolfine," Clinical and Experimental Dermatology, vol. 17, pp. 8-12, 1992.

[6] https://prvademecum.es/app/sustancias/view/1350/amorolfinahidrocloruro.

[7] https://www.drugs.com/international/amorolfine.html.

[8] http://www.farmaciasahumada.cl/fasa/MFT/PRODUCTO/ P3204.HTM.

[9] C. Wang and L. Yu, "Determination of amorolfine hydrochloride liniment by HPLC," Chinese Journal of Antibiotics, vol. 25, no. 3, pp. 226-227, 2000.

[10] Y. Gao, L. Li, J. Zhang, W. Shu, and L. Gao, "Simultaneous determination of triacetin, acetic ether, butyl acetate and amorolfine hydrochloride in amorolfine liniment by HPLC," Pakistan Journal of Pharmaceutical Sciences, vol. 25, no. 2, pp. 389-394, 2012.

[11] A. Aparna, B. Anupama, G. Vindya, and G. D. Rao, "Spectrophotometric method for the determination of amorolfine," Oriental Journal of Chemistry, vol. 26, no. 3, pp. 1207-1209, 2010.

[12] R. Stanley Crouch and T. Cullen, "Kinetic determinations and some kinetic aspects of analytical chemistry," Analytical Chemistry, vol. 70, no. 12, pp. 53-106, 1998.

[13] H. A. Mottola and D. Pérez-Bendito, "Kinetic determinations and some kinetic aspects of analytical chemistry," Analytical Chemistry, vol. 68, no. 12, pp. 257-290, 1996.

[14] Y. Ni, Y. Wang, and S. Kokot, "Multicomponent kinetic spectrophotometric determination of pefloxacin and norfloxacin in pharmaceutical preparations and human plasma samples with the aid of chemometrics," Spectrochimica Acta-Part A: Molecular and Biomolecular Spectroscopy, vol. 70, no. 5, pp. 1049-1059, 2008.
[15] G. A. Saleh, S. R. El-Shaboury, F. A. Mohamed, and A. H. Rageh, "Kinetic spectrophotometric determination of certain cephalosporins using oxidized quercetin reagent," Spectrochimica Acta Part A: Molecular and Biomolecular Spectroscopy, vol. 73, no. 5, pp. 946-954, 2009.

[16] I. A. Darwish, M. A. Sultan, and H. A. Al-Arfaj, "Novel selective kinetic spectrophotometric method for determination of norfloxacin in its pharmaceutical formulations," Talanta, vol. 78, no. 4-5, pp. 1383-1388, 2009.

[17] H. E. Abdellatef, "Kinetic spectrophotometric determination of tramadol hydrochloride in pharmaceutical formulation," Journal of Pharmaceutical and Biomedical Analysis, vol. 29, no. 5, pp. 835-842, 2002.

[18] M. R. Moghadam, S. Dadfarnia, A. M. H. Shabani, and P. Shahbazikhah, "Chemometric-assisted kinetic-spectrophotometric method for simultaneous determination of ascorbic acid, uric acid, and dopamine," Analytical Biochemistry, vol. 410, no. 2, pp. 289-295, 2011.

[19] M. Kompany-Zareh, H. Tavallali, and M. Sajjadi, "Application of generalized artificial neural networks coupled with an orthogonal design to optimization of a system for the kinetic spectrophotometric determination of $\mathrm{Hg}(\mathrm{II})$," Analytica Chimica Acta, vol. 469, no. 2, pp. 303-310, 2002.

[20] Y. Ni and Y. Wang, "Application of chemometric methods to the simultaneous kinetic spectrophotometric determination of iodate and periodate based on consecutive reactions," Microchemical Journal, vol. 86, no. 2, pp. 216-226, 2007.

[21] M. Hasani and F. Emami, "Evaluation of feed-forward back propagation and radial basis function neural networks in simultaneous kinetic spectrophotometric determination of nitroaniline isomers," Talanta, vol. 75, no. 1, pp. 116-126, 2008.

[22] A. Afkhami and M. Abbasi-Tarighat, "Application of continuous wavelet transformation to the simultaneous kinetic determination of binary mixtures," Talanta, vol. 78, no. 2, pp. 424-431, 2009.

[23] R. M. Naik, B. Kumar, and A. Asthana, "Kinetic spectrophotometric method for trace determination of thiocyanate based on its inhibitory effect," Spectrochimica Acta-Part A, vol. 75, no. 3, pp. 1152-1158, 2010.

[24] S. Abbasi, R. Valinezhad, and H. Khani, "A novel kinetic spectrophotometric method for the determination of ultra trace amount of cyanide," Spectrochimica Acta-Part A: Molecular and Biomolecular Spectroscopy, vol. 77, no. 1, pp. 112-116, 2010.

[25] S. Abbasi, H. Khani, L. Hosseinzadeh, and Z. Safari, "Determination of thiourea in fruit juice by a kinetic spectrophotometric method," Journal of Hazardous Materials, vol. 174, no. 1-3, pp. 257-262, 2010.

[26] S. M. Rancic, S. D. Nikolic-Mandic, and L. M. Mandic, "Kinetic spectrophotometric method for gold(III) determination," Analytica Chimica Acta, vol. 547, no. 1, pp. 144-149, 2005.

[27] M. G. Abdel Wahed, R. El Sheikh, A. A. Gouda, and S. Abou Taleb, "Kinetic spectrophotometric determination of gemifloxacin mesylate and moxifloxacin hydrochloride in pharmaceutical preparations using 4-chloro-7-nitrobenzo-2-oxa1,3-diazole," Journal of Spectroscopy, vol. 2014, Article ID 917234, 12 pages, 2014.

[28] A. M. Akhoundi-Khalafi and M. R. Shishehbore, "A new technique for quantitative determination of dexamethasone in pharmaceutical and biological samples using kinetic spectrophotometric method," International Journal of Analytical Chemistry, vol. 2015, Article ID 439271, 6 pages, 2015. 
[29] K. Wiber, Oxidation in Organic Chemistry (Part A), vol. 17, Academic Press, New York, NY, USA, 1965.

[30] J. Rose, Advanced Physicochemical Experiments, Pitman, London, UK, 1964. 

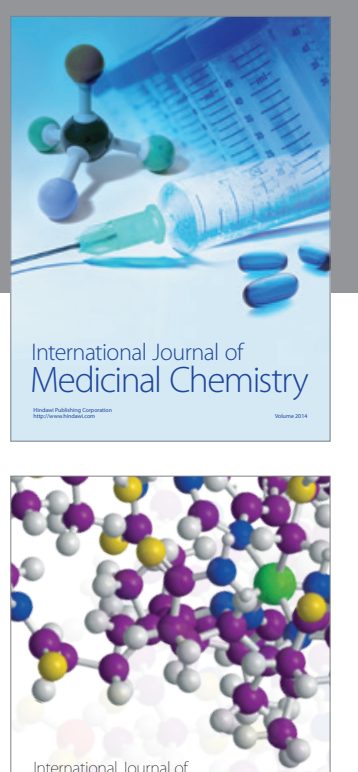

Carbohydrate Chemistry

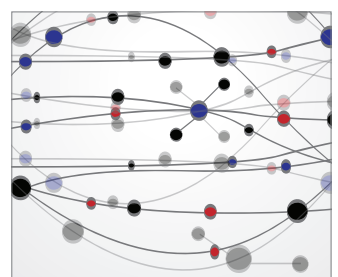

The Scientific World Journal
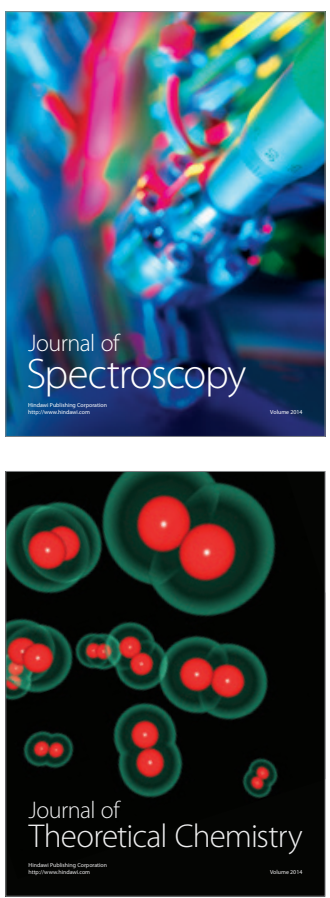
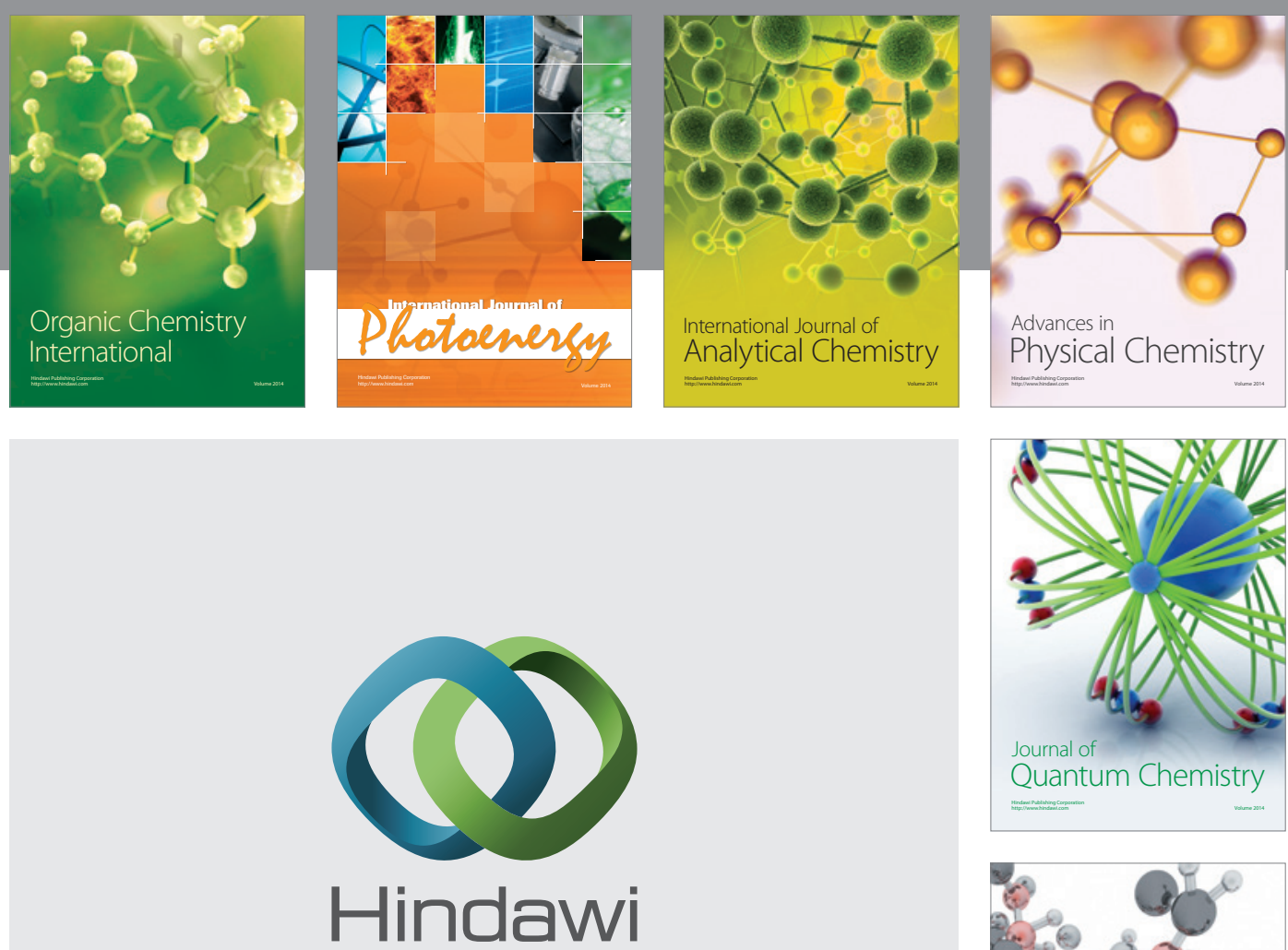

Submit your manuscripts at

https://www.hindawi.com

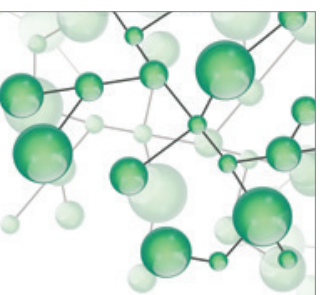

International Journal of

Inorganic Chemistry
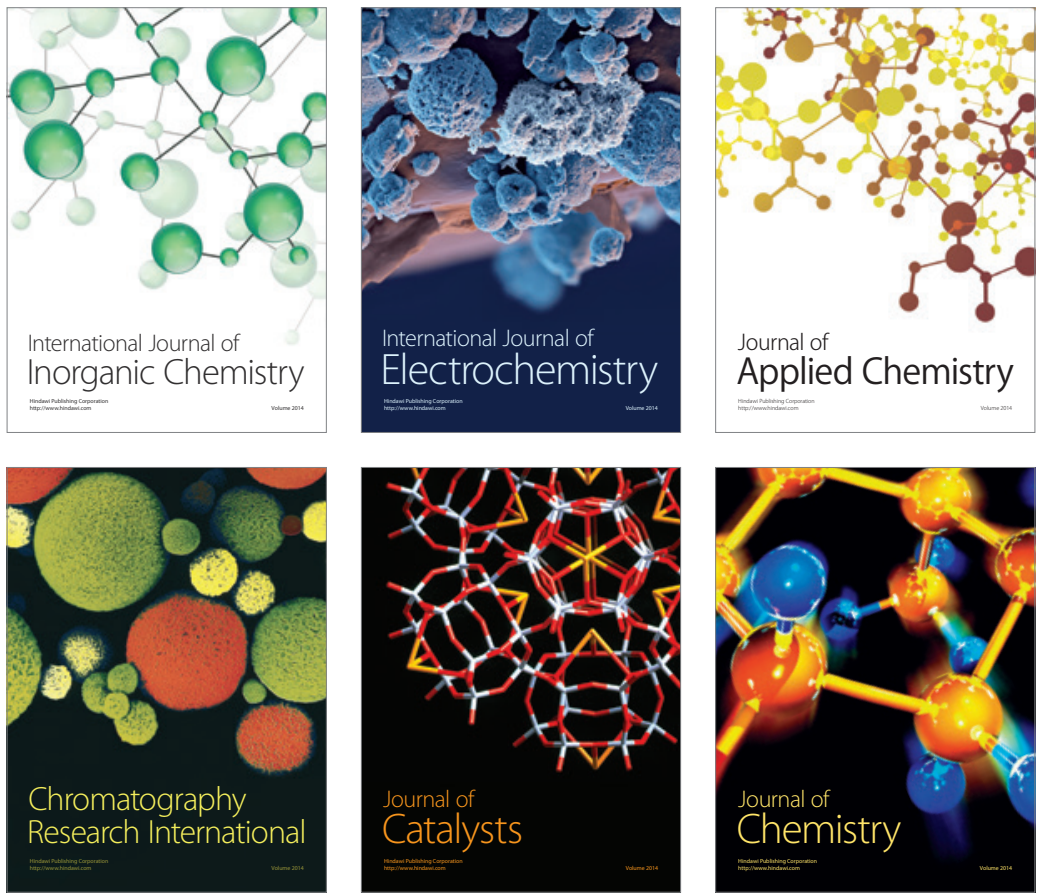

Journal of

Applied Chemistry
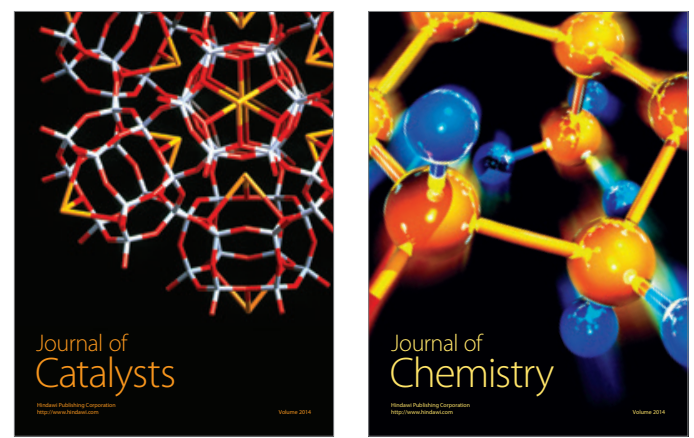
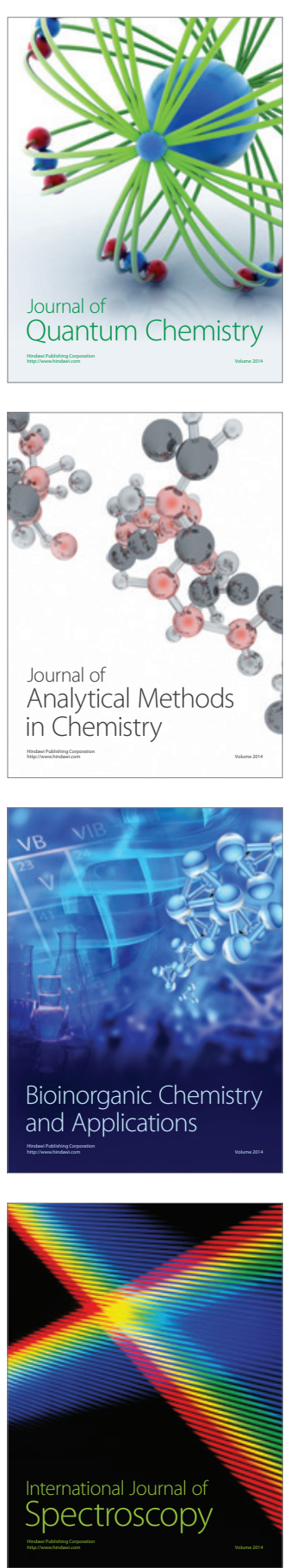